Pathophysiology

of Haemostasis and Thrombosis
Pathophysiol Haemost Thromb 2005;34:13-17

DOI: $\underline{10.1159 / 000088542}$
Received: December 12, 2004

Accepted after revision: March 15, 2005

\title{
Association of Leukocyte Activation, but Not the Common Cold, with Restenosis after Percutaneous Coronary Intervention in Patients with Angina Pectoris
}

\author{
N. Inami ${ }^{a} \quad$ S. Nomura ${ }^{b} \quad$ Y. Kimura ${ }^{a} \quad$ Y. Sutani $^{\mathrm{a}} \quad$ K. Yamada ${ }^{\mathrm{a}} \quad$ H. Nakamori ${ }^{\mathrm{a}}$ \\ N. Takahashi ${ }^{a} \quad$ N. Tsuda $^{a}$ S. Fukuhara ${ }^{b}$ T. Iwasaka ${ }^{a}$ \\ ${ }^{a}$ Second Department of Internal Medicine and ${ }^{b}$ First Department of Internal Medicine, Kansai Medical \\ University, Moriguchi, Osaka, Japan
}

\section{Key Words}

Percutaneous coronary intervention - L-Selectin, soluble $\cdot$ Common cold $\cdot$ Angina pectoris $\cdot$ Restenosis

\begin{abstract}
We investigated the relationship between the common cold and restenosis after percutaneous coronary intervention ( $\mathrm{PCl}$ ) in Japanese patients with angina pectoris, because suffering from a common cold during the follow-up period after $\mathrm{PCl}$ may be involved in the development of restenosis. In addition, we measured the soluble (s) L-selectin level early after $\mathrm{PCl}$ in patients with and without restenosis. The study group included 104 effort angina pectoris patients. We examined whether or not they had had a common cold in the 6 months following angioplasty. Finally, 88 patients, whose common cold status was known, were selected as the study subjects. Twelve patients caught a common cold after PCI. All of these patients were given antibiotics and/or anti-inflammatory agents and recovered within 2 weeks. None had clinically detectable influenza infection. Thirty-three patients suffered from restenosis and 55 did not. There was no significant difference in the restenosis frequency between effort angina pectoris patients with and without a common cold. The s $L$-selectin level was significantly in-
\end{abstract}

creased in patients with restenosis early after $\mathrm{PCl}$, whereas in patients without restenosis, $s L$-selectin remained unchanged. These findings suggest that restenosis development after $\mathrm{PCl}$ in patients with effort angina pectoris may involve leukocyte activation early after $\mathrm{PCl}$, while suffering from a common cold during the follow-up period after $\mathrm{PCl}$ has no effect.

Copyright (C) 2005 S. Karger AG, Basel

\section{Introduction}

Percutaneous coronary intervention (PCI) is an accepted revascularization procedure to treat patients with coronary artery disease [1]. However, the development of restenosis remains a serious problem, and the detailed mechanism is not understood [2-4]. PCI was previously reported to be linked to platelet activation, leading to acute ischemic events in treated patients $[5,6]$. Furthermore, in addition to platelet activation, the activations of leukocytes and endothelia by PCI represent possible influential triggers. In particular, leukocyte activation induces adhesion to endothelial cells, and this mechanism may involve cell adhesion molecules, such as $L$-selectin, and finally cause vascular complications. Thus, it is supposed that the inflammatory events induced by leuko-

\section{KARGER}

Fax +4161306 1234 E-Mail karger@karger.ch www.karger.com
(C) 2005 S. Karger AG, Basel

$1424-8832 / 05 / 0341-0013 \$ 22.00 / 0$

Accessible online at:

www.karger.com/pht
Shosaku Nomura, MD

First Department of Internal Medicine, Kansai Medical University

10-15 Fumizono-cho, Moriguchi

Osaka 570 (Japan)

Tel. +8166992 1001, Fax +81 72532 1113, E-Mail shosaku-n@mbp.ocn.ne.jp 
cytes may play a pathogenic role in restenosis development after PCI [7].

On the other hand, several intriguing associations noted in the epidemiology of coronary artery disease have suggested a potential influence of infections. For example, the rates of myocardial infarction and cardiac death increase in winter and after influenza epidemics $[8,9]$. There is also strong evidence to suggest that viral infections play a role in restenosis development after PCI. Symptomatic restenosis is a common complication of coronary angioplasty, and occurs in nearly $15 \%$ of patients receiving stents. A recent study demonstrated that patients with positive titers for cytomegalovirus had a much higher rate of restenosis 6 months after angioplasty [10]. Gurfinkel et al. [11] reported that influenza vaccination may reduce the risk of death and ischemic events in patients suffering from infarction and those recovering from angioplasty during the flu season. These observations suggest that influenza after PCI is a risk factor for restenosis.

In the present study, we investigated the relationship between the common cold and restenosis after PCI in Japanese patients with angina pectoris, since suffering from a common cold during the follow-up period after PCI may be involved in the development of restenosis. In addition, we measured the soluble (s) $L$-selectin level early after PCI in patients with and without restenosis.

\section{Subjects and Methods}

The study group included 104 effort angina pectoris (AP) patients. All patients gave informed consent to participate in the study in accordance with the Declaration of Helsinki. None of the patients had suffered from inflammatory and cerebrovascular diseases within the previous 3 months, and none had clinically detectable renal, hepatic, infectious or malignant diseases. We examined whether or not the patients had had a common cold during 6 months after angioplasty. Finally, 88 patients whose common cold status was known were selected as the study subjects. The clinical profiles of the 88 patients are shown in table 1 .

\section{Angioplasty Procedure and Follow-Up Evaluation}

PCI was performed according to standard techniques. The four coronary arteriograms obtained were analyzed by an experienced cardiologist. Measurements were made in a single projection that showed the most severe stenosis. All patients underwent stent insertion, followed by aspirin (100 mg/day) and ticlopidine $(200 \mathrm{mg} /$ day) administration. An initial blood sample was obtained before intervention, and then subsequent samples were obtained after 1 and 7 days. Patients returned for clinical control after 15 days and then at 1, 3 and 6 months. Patients were readmitted for follow-up coronary angiography 6 months after the angioplasty. Coronary lesions were assessed by quantitative coronary angiographic mea-
Table 1. Clinical profiles of the effort angina pectoris patients

\begin{tabular}{lc}
\hline Sex, M/F & $69 / 19$ \\
Age, years & $64 \pm 9$ \\
BMI, kg/m ${ }^{2}$ & $25.1 \pm 3.5$ \\
T-CHO, mg/dl & $194 \pm 33$ \\
HDL, mg/dl & $41 \pm 8$ \\
Coronary risk factor & \\
$\quad$ Smoking & $42(47.5 \%)$ \\
$\quad$ Hypertension & $43(48.5 \%)$ \\
$\quad$ Diabetes mellitus & $27(30.5 \%)$ \\
Stent Artery & \\
$\quad$ RCA/LAD/CX & $19 / 43 / 26$ \\
$\quad$ Stent size, mm & $2.95 \pm 0.39$ \\
$\quad$ Stent diameter, mm & $18.6 \pm 4.5$ \\
Common cold & $12(11.3 \%)$ \\
\hline
\end{tabular}

Data represent the means $\pm \mathrm{SD}$. BMI $=$ Body mass index; T-CHO = total cholesterol; HDL = high-density lipoprotein; $\mathrm{RCA}=$ right coronary artery; $\mathrm{LAD}=$ left anterior descending; $\mathrm{CX}=$ circumflex.

surements using a computer-based QUANTCOR system (Siemens). The quantitative measurements were performed on enddiastolic frames from angiograms by 1 investigator who was unaware of the study design. The reference diameter, lesion length, and minimal lumen diameter were measured before and after PCI and at the time of the follow-up coronary angiography. On the basis of these measurements, we obtained the value of acute gain (minimal lumen diameter after PCI minus minimal lumen diameter before PCI) and late lumen loss (minimal lumen diameter after PCI minus minimal lumen diameter at follow-up angiography) for the lesions. Restenosis was defined as $>50 \%$ diameter stenosis at follow-up angiography.

\section{Measurement of sL-Selectin}

Blood samples were collected from the patients into plastic tubes. Blood was allowed to clot at room temperature for at least $1 \mathrm{~h}$, and then serum was withdrawn after centrifugation for $20 \mathrm{~min}$ at $1,000 \mathrm{~g}$ and $4^{\circ} \mathrm{C}$ and store at $-30^{\circ} \mathrm{C}$ until analysis. As positive controls, we used recombinant products in addition to the standard solutions provided in the commercial assay kits. The $\mathrm{s} L$-selectin enzyme-linked immunosorbent assay kit used was obtained from BioSource International Inc. (Camarillo, Calif., USA). For measurement of $\mathrm{s} L$-selectin in serum, the kit was used according to the manufacturer's instructions.

\section{Statistical Analysis}

The results are shown as the mean \pm SD. The significance of differences among variables was determined by analysis of variance (ANOVA). Student's t test analysis was used for statistical comparisons, and $\mathrm{p}$ values of $<0.05$ were considered significant. 
Table 2. Clinical profiles of patients with and without restenosis

\begin{tabular}{lcll}
\hline & Restenosis (+) & Restenosis (-) & p value* \\
\hline Patients & 33 & 55 & \\
Sex, M/F & $24 / 9$ & $45 / 10$ & NS \\
Age, years & $62 \pm 10$ & $65 \pm 10$ & $\mathrm{NS}$ \\
BMI, kg/m ${ }^{2}$ & $25.0 \pm 3.6$ & $25.0 \pm 3.7$ & $\mathrm{NS}$ \\
T-CHO, mg/dl & $189 \pm 33$ & $203 \pm 34$ & $\mathrm{NS}$ \\
HDL, mg/dl & $39.0 \pm 7.0$ & $42.0 \pm 9.6$ & $\mathrm{NS}$ \\
Coronary risk factor & & & \\
$\quad$ Smoking & $16(48 \%)$ & $26(47 \%)$ & $\mathrm{NS}$ \\
$\quad$ Hypertension & $16(48 \%)$ & $27(49 \%)$ & $\mathrm{NS}$ \\
$\quad$ Diabetes mellitus & $10(30 \%)$ & $17(31 \%)$ & $\mathrm{NS}$ \\
Stent artery & & & \\
$\quad$ RCA/LAD/CX & $8 / 15 / 10$ & $11 / 28 / 16$ & $\mathrm{NS}$ \\
$\quad$ Stent size, mm & $2.78 \pm 0.35$ & $3.12 \pm 0.42$ & $\mathrm{NS}$ \\
$\quad$ Stent diameter, mm & $19.2 \pm 5.1$ & $16.9 \pm 3.9$ & $\mathrm{NS}$ \\
Medication & & & \\
$\quad$ Statin & $5(15.2 \%)$ & $10(18.2 \%)$ & $\mathrm{NS}$ \\
$\quad$ ARB & $7(21.2 \%)$ & $13(23.7 \%)$ & $\mathrm{NS}$ \\
$\quad$ ACE inhibitor & $6(18.2 \%)$ & $9(16.4 \%)$ & $\mathrm{NS}$ \\
$\quad$ Ca blocker & $5(15.2 \%)$ & $9(14.5 \%)$ & $\mathrm{NS}$ \\
Common cold & $3(9.9 \%)$ & $9(16.3 \%)$ & NS \\
\hline
\end{tabular}

Data represent the means \pm SD. NS $=$ Not significant; $\mathrm{T}-\mathrm{CHO}=$ total cholesterol; $\mathrm{HDL}=$ high-density lipoprotein; $\mathrm{BMI}=$ body mass index $; \mathrm{RCA}=$ right coronary artery; $\mathrm{LAD}=$ left anterior descending; $\mathrm{CX}=$ circumflex; $\mathrm{ARB}=$ angiotensin-II receptor blocker.

* $\mathrm{p}$ value for comparison of the values of the 2 groups.

\section{Results}

Twelve patients caught a common cold after PCI (table 1). All of these patients were given antibiotics and/or anti-inflammatory agents, and recovered within 2 weeks. None had clinically detectable influenza infection.

The clinical profiles of the angina pectoris patients with and without restenosis are shown in table 2. Thirtythree patients suffered from restenosis and 55 did not. We did not observe any differences between the clinical profiles of these 2 groups.

The $s L$-selectin values in the 2 groups are shown in figure 1. A significant and time-dependent increase in $\mathrm{s} L$ selectin was observed in the restenosis group (before vs. 1 day, 0 vs. $0.18 \pm 0.12, \mathrm{p}<0.05$; before vs. 7 days, 0 vs. $0.36 \pm 0.13, \mathrm{p}<0.05)$.

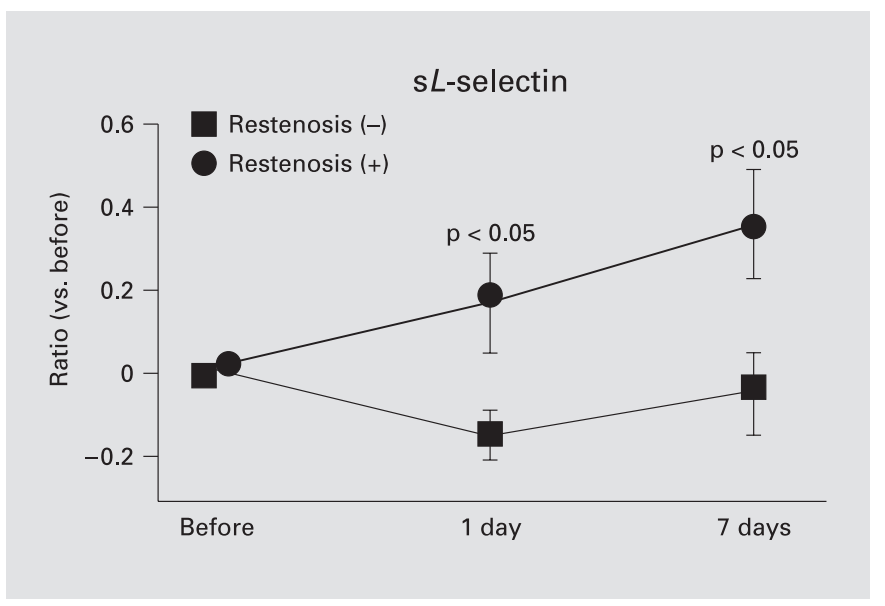

Fig. 1. Changes in the $s L$-selectin level after PCI. The mean \pm SEM values for each group are shown.

\section{Discussion}

Restenosis after PCI is still a major clinical problem [12], and its pathophysiology has not yet been elucidated. It is supposed that vessel injury may initiate an inflammatory response that accelerates the recruitment of leukocytes. As described in the theory of 'response to injury' by Ross [13], damage to the endothelium is one of the factors in the development of vascular events. The tethering of leukocytes to the endothelial cell surface is the initial critical event in leukocyte recruitment, and this interaction between the cells is essential for vascular homeostasis and competent immune-inflammatory responses in vivo $[14,15]$. Therefore, leukocyte activation by inflammation could be an important cause of endothelial damage. Bacterial and viral infections may also stimulate an autoimmune reaction through molecular mimicry that prolongs a chronic inflammatory process through both specific and nonspecific mechanisms [16]. Gurfinkel et al. [11] reported that influenza infection had an effect on restenosis development after PCI. In the present study, we investigated the possibility that a common cold after PCI may participate in restenosis development in Japanese angina pectoris patients. However, we did not find any significant relationship between the common cold and restenosis after PCI. There have been some reports concerning the relationships between infectious diseases and coronary events $[17,18]$. Regarding the mechanism of virus-associated coronary events, Gurfinkel et al. [11] suggested that the most important event for triggering coagulation may be virus-induced secretion of the power- 
ful coagulant tissue factor [19]. In the present study, the elevation status of the tissue factor in the patients with a common cold was unknown. However, all the patients recovered within 2 weeks. In addition, they did not suffer an episode of thrombosis accompanying the common cold. The reason for the discrepancy between the viral infection-related coronary events in the current study and those in Gurfinkel et al. [11] is unknown. Hence, we consider that the limitation of the present study is the inability to confirm the conditions of the common cold in the patients, such as differences in the degree of infection or the use of anti-inflammatory drugs. However, a longer follow-up of the same study did not always support all of the initial observations [20]. In addition, several large clinical trials failed to show any benefit of antibiotics therapy in the prevention of coronary artery disease $[21,22]$. Therefore, further investigations using selected common cold patients are still required.

We next evaluated the effects of PCI on the level of $\mathrm{s} L$-selectin. The level of $\mathrm{s} L$-selectin was significantly increased in patients with restenosis after PCI compared to those without restenosis. In addition, differences existed between 1 and 7 days after PCI. $L$-Selectin is an adhesion molecule belonging to the selectin family [23]. L-Selectin mediates the 'rolling' attachment of activated neutrophils to the vessel wall at sites of inflammation, which occurs as a step before 'strong adhesion'. Inoue et al. [24-26] demonstrated that balloon coronary angioplasty downregulated $L$-selectin on circulating neutrophils at $24-48 \mathrm{~h}$ after the procedure, possibly in response to the ballooninduced injury and inflammation of the atherosclerotic vessel wall. In addition, these findings were more prominent in patients who experienced subsequent restenosis. In the present study, sL-selectin increased in a time-dependent manner in patients with restenosis after PCI. Inoue et al. [24-26] measured the $L$-selectin level on the neutrophils by flow cytometry, and found that it decreased after PCI. They therefore concluded that downregulation of $L$-selectin, which may be due to shedding, was present within the coronary circulation after PCI. Such shedding of $L$-selectin would cause an elevation in $\mathrm{s} L$-selectin in the peripheral blood vessels. It is unknown whether all of the elevated $\mathrm{s} L$-selectin levels observed in the present study were derived from neutrophils. Some inflammatory cells other than neutrophils are reported to be implicated in the inflammatory process in the PCI-injured wall, such as monocytes or T lymphocytes [27]. In addition, some chemokines are implicated in the recruited leukocyte. Cipollone et al. [7] demonstrated upregulated levels of monocyte chemoattractant protein-1 after
PCI and found that monocyte chemoattractant protein-1 levels were correlated with a risk for restenosis. Furthermore, Gaspardone et al. [28] showed a correlation between C-reactive protein after stent placement and a propensity for restenosis. These previous reports suggest the importance of inflammation and leukocytes in the development of restenosis after PCI, and our results support these findings.

What is the mechanism of leukocyte activation after PCI? We consider that one of the mechanisms involves RANTES (regulated on activation normally T-cell expressed and secreted). RANTES is a proinflammatory member of the $\mathrm{C}-\mathrm{C}$ chemokine family and a potent chemoattractant of memory $\mathrm{T}$ lymphocytes, monocytes, eosinophils and basophils [29]. RANTES may also activate specific effector cell populations of these cells [30]. We previously reported that RANTES was significantly increased in acute coronary syndrome, and that intervention improved this elevation of RANTES [31, 32]. However, we preliminarily observed that RANTES was increased after PCI in patients with restenosis. The collection of patients for a statistical analysis of this aspect is currently underway.

In conclusion, there was no significant difference in the restenosis frequency between effort angina pectoris patients with and without a common cold after PCI. The $\mathrm{s} L$-selectin level in patients with restenosis was significantly increased at an early period after PCI, while that in patients without restenosis remained unchanged. These findings suggest that restenosis development after PCI in patients with effort angina pectoris may involve leukocyte activation at an early period after PCI, while suffering from a common cold during the follow-up period after PCI has no effect. 


\section{References}

1 Landau C, Lange RA, Hillis LD: Percutaneous transluminal coronary angioplasty. $\mathrm{N}$ Engl $\mathrm{J}$ Med 1994;330:981-993.

-2 Serruys PW, Luijten HE, Beatt KJ, Geuskens $\mathrm{R}$, de Feyter PJ, van den Brand M, Reiber JH, ten Katen HJ, van Es GA, Hugenholtz PG: Incidence of restenosis after successful coronary angioplasty: A time-related phenomenon. A quantitative angiographic study in 342 consecutive patients at $1,2,3$, and 4 months. Circulation 1988;77:361-371.

-3 Nobuyoshi M, Kimura T, Nosaka H, Mioka S, Ueno K, Yokoi H, Hamasaki N, Horiuchi H, Ohishi $\mathrm{H}$ : Restenosis after successful percutaneous transluminal coronary angioplasty: Serial angiographic follow-up of 229 patients. J Am Coll Cardiol 1988;12:616-623.

4 Califf RN, Fortin DF, Frid DJ, Harlan WR 3rd, Ohman EM, Bengtson JR, Nelson CL, Tcheng JE, Mark DB, Stack RS: Restenosis after coronary angioplasty: An overview. J Am Coll Cardiol 1991;17:2B-13B.

5 Fitzgerald DJ, Roy I, Catella F, FitzGerald GA: Platelet activation in unstable angina. $\mathrm{N}$ Engl J Med 1986;315:983-989.

-6 Steele PM, Chesebro JH, Stanson AW, Holmes DR Jr, Dewanjee MK, Badimon L, Fuster $\mathrm{V}$ : Balloon angioplasty. Natural history of the pathophysiological response to injury in a pig model. Circ Res 1985;57:105-112.

7 Cipollone F, Marini M, Fazia M, Pini B, Iezzi A, Reale M, Paloscia L, Materazzo G, D'Annunzio E, Conti P, Chiarelli F, Cuccurullo F, Mezzetti A: Elevated circulating levels of monocyte chemoattractant protein-1 in patients with restenosis after coronary angioplasty. Arterioscler Thromb Vasc Biol 2001;21: 327-334.

8 Woodhouse PR, Khaw KT, Plummer M, Foley A, Meade TW: Seasonal variations of plasma fibrinogen and factor VII activity in the elderly: Winter infectious and death from cardiovascular disease. Lancet 1994;343:435-439.

-9 Tillet HE, Smith JWG, Gooch CD: Excess death attributable to influenza in England and Wales: Age at death and certified cause. Int J Epidemiol 1983;12:344-352.

10 Zhou YF, Leon MB, Maclawiw MA, Popma JJ, Yu ZX, Finkel T, Epstein SE: Association between prior cytomegalovirus infection and the risk of restenosis after coronary atherectomy. N Engl J Med 1996;335:624-630.

-11 Gurfinkel EP, de la Fuente RL, Mendiz O, Mautner B: Influenza vaccine pilot study in acute coronary syndromes and planned percutaneous coronary interventions - The FLU Vaccination Acute Coronary Syndrome (FLUVACS) Study. Circulation 2002; 105: 2143-2147.
12 Smith SC, Dove JT, Jacobs AK, Kennedy JW, Kereiakes D, Kern MJ, Kuntz RE, Popma JJ, Schaff HV, Williams DO, Gibbons RJ, Alpert JP, Eagle KA, Faxon DP, Fuster V, Gardner TJ, Gregoratos G, Russell RO, Smith SC Jr, American College of Cardiology/American Heart Association task force on practice guidelines (Committee to revise the 1993 guidelines for percutaneous transluminal coronary angioplasty), Society for Cardiac Angiography and Interventions: ACC/AHA Guidelines for percutaneous coronary intervention (revision of the 1993 PTCA guidelines) - executive summary. A report of the American College of Cardiology/American Heart Association task force on practice guidelines (Committee to revise the 1993 guidelines for percutaneous transluminal coronary angioplasty) endorsed by the Society for Cardiac Angiography and Interventions. Circulation 2001;103:3019- 3041.

13 Ross R: Atherosclerosis - An inflammatory disease. N Engl J Med 1999;340:115-126.

14 Dustin ML, Springer TA: Role of lymphocyte adhesion receptors in transient interaction and cell locomotion. Annu Rev Immunol 1991;9: 27-66.

15 Carlos TM, Harlan JM: Leukocyte-endothelial adhesion molecules. Blood 1994;84:20682101.

16 Bachmaier K, Neu N, de la Maza LM, Pal S, Hessel A, Penninger JM: Chlamydia infections and heart disease linked through antigenic mimicry. Science 1999;283:1335-1339.

17 Libby P, Egan D, Skarlators S: Roles of infectious agents in atherosclerosis and restenosis: An assessment of the evidence and need for future research. Circulation 1997;96:40954103 .

18 Naghavi M, Barlas Z, Siadaty S, Naguib S, Madjid M, Casscells W: Association of influenza vaccination and reduced risk of recurrent myocardial infarction. Circulation 2000;102 3039-3045.

19 Key NS, Vercellotti GM, Winkelmann JC, Moldow CF, Goodman JL, Esmon NL, Esmon CT, Jacob HS: Infection of vascular endothelial cells with herpes simplex virus enhances tissue factor activity and reduces thrombomodulin expression. Proc Natl Acad Sci USA 1990;87:7095-7099.

20 Gurfinkel EP, Leon de la Fuente R, Mendiz O, Mautner B: Flu vaccination in acute coronary syndromes and planned percutaneous coronary interventions (FLUVACS) Study. Eur Heart J 2004;25:25-31.
21 Luchsinger JA, Pablos-Mendez A, Knirsch C, Rabinowitz D, Shea S: Relation of antibiotic use to risk of myocardial infarction in the general population. Am J Cardiol 2002;89:1821.

22 Muhlestein JB: Secondary prevention of coronary artery disease with antimicrobials: Current status and future directions. Am J Cardiovasc Drugs 2002;2:107-118.

23 Butcher EC: Leukocyte-endothelial cell recognition: Three (or more) steps to specificity and diversity. Cell 1991;67:1033-1036.

24 Inoue T, Sakai Y, Fujito T, Hoshi K, Hayashi T, Takayanagi K, Morooka S: Clinical significance of neutrophil adhesion molecules expression after coronary angioplasty on the development of restenosis. Thromb Haemost 1998;79: 54-58.

25 Inoue T, Sohma R, Miyazaki T, Iwasaki Y, Yaguchi I, Morooka S: Comparison of activation process of platelets and neutrophils after coronary stent implantation versus balloon angioplasty for stable angina pectoris. Am J Cardiol 2000;86:1057-1062.

26 Inoue T, Uchida T, Yaguchi I, Sakai Y, Takayanagi K, Morooka S: Stent-induced expression and activation of the leukocyte integrin Mac-1 is associated with neointimal thickening and restenosis. Circulation 2003;107:1757-1763.

27 Welt FGP, Rogers C: Inflammation and restenosis in the stent era. Arterioscler Thromb Vasc Biol 2002;22:1769-1776.

-28 Gaspardone A, Crea F, Versaci F, Tomai F, Pellegrino A, Chiariello L, Gioffre PA: Predictive value of C-reactive protein after successful coronary-artery stenting in patients with stable angina. Am J Cardiol 1998;82:515-518.

$\checkmark 29$ Baggiolini M, Deward B, Moster B: Interleukin- 8 and related chemotactic cytokines - CXC and CC chenokines. Adv Immunol 1994;55: 97-179.

30 Kameyoshi Y, Dorschner A, Mallet AI, Christophers E, Schroder JM: Cytokine RANTES released by thrombin-stimulated platelets is a potent attractant for human eosinophils. J Exp Med 1992;176:587-592

- 31 Matsumoto N, Nomura S, Kamihata H, Kimura Y, Iwasaka T: Association of platelet-derived microparticles with $\mathrm{C}-\mathrm{C}$ chemokines on vascular complication in patients with acute myocardial infarction. Clin Appl Thromb Hemost 2002;8:279-286.

32 Nomura S, Uehata S, Saito S, Osumi K, Ozeki Y, Kimura Y: Enzyme immunoassay detection of platelet-derived microparticles and RANTES in acute coronary syndrome. Thromb Haemost 2003;89:506-512. 